\title{
Learning without Teachers (?): a study of Herman Hesse's Siddhartha
}

\author{
Nitya Raj Bhattarai \\ Lecturer, Hetauda School of Management and Social Sciences
}

\begin{abstract}
The title character in Herman Hesse's novel, Siddhartha, tried to revolt against teacher-centered teaching and started his own journey to get enlightenment through self-quest or selfinvestigation. However, this research paper studies Siddhartha declaration acquiring enlightenment through his self- education with contradictory ideas and marks a direct or indirect involvement of teachers in his education. The essay supports its line of departure giving the background of Siddhartha's journey of enlightenment, studying his self- education as a part of teacherbased education by answering the question in two different topics (why did he leave teachers? / Can education be possible without teachers?) and finally draw its conclusion. Though Siddhartha is an artistic work and the ideas of this paper may not be applicable in the real classroom scenario, the reliability of the analysis of the book would become fruitful since it gives some perspectives to understand our practices philosophically- if not practically.
\end{abstract}

Key words: Teacher- centric teaching, enlightenment, selfsalvation/ self- enlightenment, journey of education 


\section{Siddhartha Journey of Enlightenment}

Siddhartha's academic journey of enlightenment is studied in two parts: enlightenment through direct and indirect involvement with teachers and enlightenment through self- education. The first part of his academic journey started from finding and selecting different teachers to get the way for salvation through enlightenment. His second stage of journey started when he became disillusioned and realized that enlightenment was not possible through teachers and started his self-journey of knowledge acquisition.

The first part of his journey started from his home where he learned different things from his venerable gurus and his own father. His acquisition of knowledge was mostly based on chanting pious mantras from Vedas and Puranas and doing daily religious practices. Later, "he had started to suspect his venerable father and his other teachers," that they could not give him essential knowledge and guide him to the state of enlightenment (5).

Then, Siddhartha followed samanas, the ascetic, in their jungle hermitage. Here, he practiced his education by suppressing senses which he called "merciless self-denial" (7). He enjoyed the time with them. It is the life that he desired and for which he had left his home and the dear family. Expressing Siddhartha's success of academic journey with samanas, the narrator writes "Siddhartha learned a lot when he was with the samanas" (13). However, his time with them did not last long as expected. After mastering the skills of self-control, fasting and thinking, for three years, he lost interest in them. He sarcastically replies to Govinda that "What I have learned, being among the Samans, up to this day, I could have learned more quickly and by simpler means" (13). He, then, left Samanas and started searching for a new teacher.

His search for a new teacher got its destination when he heard about Gotama. However, after spending some time with Gomata, his perception towards him changed. His attraction to

Gotama turned to repulsion. He thought that "nobody will obtain salvation by means of teaching"- and not even by suppressing senses as his teacher said (26). With this 
realization, he left Gotama and started his second part of the journey of his life as an independent/ autonomous learner.

In the first phase of this journey; his senses took him to a city where he met Kamala, a courtesan, and Kamaswami, a businessman. Here, he learned the art of love making from Kamala and the art of doing business from Kamaswami. Soon, he was again fed up with self-education and reached Vasudeva, the ferryman at the riverside. His quest for so called self-education got its destination here under the guidance of the river and Vasudeva himself.

\section{Siddhartha's self- enlightenment: a journey of soul under the guidance of teachers}

Siddhartha's journey of salvation, which was started from his childhood, passed on from different teachers and got its culmination with his so-called self- exploration. Later, he denied any involvement of teachers in his final achievement because he did not have any "wish to have a teacher and listen to teaching" (29). However, the reality was that he was educated in five different places and with seven different teachers. They are: at home with his father and other Brahmin gurus, in the jungle with samanas, at Jetavana with Gotama, in the city with Kamala and Kamaswami, and at the river side with Vasudeva and the river. He termed the learning of first three places as teacher based learning and learning of last two places as self- learning.

His relationship with the teachers is also affected with this division. He accepts that his education in the first three places was pursued under teachers, but he calls it meaningless since he does not learn anything from them. More than that, in the last two places, he accepts that he learns and reaches the path of enlightenment, but he calls it "selflearning"- and denies any presence of teachers here.

Is learning possible without teachers? The issue of self- learning is a controversial thing to explain. Self- learning must have its source somewhere- may be in the form of motivation if not a direct involvement with teachers. Here, it is reliable to study Siddhartha ideas of self- learning with Sanghais Yan (2012) idea on "autonomous learning" (p. 557). In her article, Yan redefines the idea of autonomous learning and posits an important role 
of a teacher in such a process. She believes though learner may avoid direct being in contact with the teacher; however, "teachers' motivation or encouragement" is a key for their guidelines for getting self- knowledge (p. 561). Similarly, postmodern thinkers also reject the ideas of "autonomous knower" (Grenz 1996, p. 8). They believe that knowledge is a cultural construct and it is relational society and the environment. With the notion of Yan' ideas of presence of teachers in autonomous learning and postmodernists ideas of relational study of knowledge, we find Siddhartha belief of self- learning is full of irony because his activities have just gone opposite to what he meant (Colebrook, 2004, p. 1).

\section{Why did Siddhartha Leave Teachers?}

Siddhartha left three teachers: his gurus at home, samanas in the jungle and Gotama. His first reason for leaving all these teachers was that they were incapable of giving him the education that he wanted. That is, Siddhartha denied the worthiness of teachers in his journey of enlightenment. However, there are multiple occasions in the text which show how he used the skills and the knowledge that he learned from his teachers to achieve his higher goals. As he was leaving samanas to join Gotama, he used the knowledge that the old samana taught him "to paralyze him (the samana)" (19). Siddhartha had the same attitude towards Gotama, too. After the first sermons from Gotama, he realized that salvation could not be obtained by following a teacher, and he left to find the way for self-salvation.

Siddhartha's another reason for leaving the teachers was that he believed their teaching was based on suppression of senses- but not use of senses. He believes senses are the source of knowledge from nature, he started his own journey where got educated by using senses. But his faith of getting knowledge with sensual experience was turned to be false. As he was leaving Kamala and Kamalaswami he asked himself "Was it necessary to live for this? (62)". His use of the rhetorical question confirmed his answer that he wasted his time in the race of sensual pleasures which did not lead him to his destination.

Leaving a teacher is a natural activity. After getting one level of knowledge from a certain teacher, it is our tendency to proceed to the next level of knowledge and probably from the next teachers. However, in such conditions we acknowledge the teacher and their role as essential in our part of the journey. Surprisingly, no such thing is seen in Siddhartha. 
Siddhartha left the teachers neither because they were incapable of teaching nor their method of teaching was wrong. He left them because he realized that he got the portion of knowledge that he should get from them.

Of course, Siddhartha has a hunger of knowledge. That is, he has a passion for learning without limits (Hart, 2004). Unlike his gurus, he does not want to limit himself on understanding some layers of truth. He wants to go for a deeper level understanding all the layers of truth and reach to the state of enlightenment. However, he does not have this hunger from the time of birth. In the past, he was happy with the life he was living. Later, the more he is educated the more hunger in him deepened. Role of his teacher is always supportive for him to arouse hunger within him.

It is clear that his teacher, of course, cannot satisfy his hunger completely, but it is they who plant the seed of knowledge in his mind and motivate him for further study. It was impossible to quench his thirst for knowledge by a single teacher because "it is impossible to know everything about anything" (Lesikar and Petit, 1996, p. 43). Every time he is in contact with a teacher he got all the knowledge the teachers possess, but he finds that only a part of knowledge. This leads him to doubt on the competency of his teachers. This doubt generates a kind of confusion in his mind and he can not understand the difference between being incomplete to being incompetent.

Siddhartha's skeptical attitude on the competency of his teacher and heeding for knowledge through self- exploration reflect the $18^{\text {th }}$ century enlightenment trend within him. In the age of enlightenment, people were more concerned about searching knowledge and attempted to know truth to understand the basis of reality. In The Enlightenment, Dorinda Utram (2019) finds essence of enlightenment in knowing truth which itself dwells on reason. Dorinda quotes Moses Medelssohn and links enlightenment with reasons developed in an individual where "enlightenment refers to as yet an uncompleted process of the education in the use of reason" (p. 1). In the same way, William Bristow (2017) defines enlightenment in terms of Rene Descates idea of rationality. According to Descartes, the essence of rationality got its basis on doubt. Here, doubt particularly revolves on the authoritative source of knowledge and generally it can be applied to all proportion that can 
be doubted. This very doubt on mainstream thought, with the evolution rationality, draws a person near to truth and turns him or her into maturity. William Bristow relates maturity with knowledge and defines it as a capacity in which an individual may work as an autonomous learner.

Following the ides of Descartes and Bristow, Siddhartha journey as an autonomous learner can be studied as his attempt for turning from immaturity to maturity. The newly grown rationality in Siddhartha, and his self- assurance and doubting on the established teaching trend of that time signify maturity within him. Siddhartha was not matured from the time of his birth. The more he goes on studying, the more he becomes matured. It is clear that he did not get ultimate maturity or enlightenment- neither from his teachers nor from his so called self- education, because that is impossible. Nevertheless, he believes that his last stage of journey as a stage of self- salvation, and become happy that his journey of enlightenment gets its aim. However, he discounts all the other steps, which were important and added up different bricks to shape his final steps for maturity. He behaves as if this final stage is a unique and detached from every other stage he has taken previously. Nonetheless, knowledge/maturity is not objective that exists on its own. It is always relational.

Relational study of knowledge is the dominant ideas of postmodern thinkers. Postmodern thinkers like Derrida, Foucault and Rorty believe that there is no objective point for a level of knowledge (maturity for enlightenment thinkers) that one can get in his/her one attempt (Grenz, 1996). Summarizing the ideas of these thinkers, Grenz in $A$ Primer on Postmodernism writes "knowledge cannot be merely objective, say the postmoderns, because the universe is not mechanistic or dualistic, but rather historical, relational and personal" (p. 7). Following the study of Grenz, we can say that Siddhartha's final stage of enlightenment, if it so, is not detached from all his tenures with previous teachers. He was not able to get the stage as a boy staying with his family. He left his home, and started his education with different teachers. The more he got educated, the more he prepared himself, directly or indirectly, to architect the route for his final destination. That is, the knowledge that he acquired from his father, samanas, Gotama and even Kamala 
and Kamaswami has direct and indirect contribution in his life which makes him able to reach at this final goal of salvation.

Siddhartha success of gaining salvation/ enlightenment proves that his teachers were incomplete, not incompetent. They only possess a limited knowledge of their own field which cannot satisfy his quest. The incomplete knowledge of the teachers does not justify Siddhartha's charge that they are incompetent. Knowledge is not objective; it is always relational, and depends on perspective or interpretation. Such a nature of knowledge is reflected on postmodernists' ideas that "knowledge is always incomplete" (p. 8). In this sense, we cannot assume a single person possess a complete knowledge. Knowledge is fluid and it highly depends on the perception, perspective and the interpretation of the receiver. Every person has different perception and their perception determines their perspective. Siddhartha always has a changing perspective towards his teachers. Before getting education from them, he admired everything they do; but after getting a level of education, he changes his perception and also the perspective. His changing perspective leads him to jumps to a conclusion that they are incompetent.

The role of a teacher is determined by the expertise of his study. All the teachers are not expertise in every field; they have some limited area of expertise. Siddhartha was hungry for knowledge. Salvation through knowledge was his soul goal. The time he realized that his teachers have some limitations: neither they transform their own enlightenment to others through preaching nor could they give the complete knowledge needed for that, he left them. However, the plant of his knowledge got its seeds from all those teachers whom he neglected.

\section{IV.Did Siddhartha learn without Teachers?}

Siddhartha's independent learning is the shadow of his previous teachers. Equally, it shows the impression of other common people or things which were not professional teachers but were a key source of knowledge for him. The role of the teacher is not determined by his/ her being a human professional teacher. All the people whom we met and interacted in our daily life can be our teacher if we learn anything from them. The same concept applies to plants and animals. Thus, teachers should be identified on the basis of 
the pupils' reception of knowledge- not on the basis of whether he/ she is a professional teacher or not. A philosophical discussion of a teacher is determined on the basis of values teachers should aim to develop in their students. (Shim, 2008, p. 517).

Following Shim's ideas, a teacher is identified on the basis of whether he is a source of value or not. That source can be either a human being, or a nature or even a person unrecognized (inner self). Getting any sense of knowledge, ideas or values deliberately from these sources make them teachers. So we cannot deny the presence of teaching if there is any type of deliberate learning. Explaining the relationship between teaching and learning Sung Hwan Shim writes: "learning does not happen alone as a result of a totally independent act of teaching" (p.516). The idea is clear that we cannot separate learning from teaching. In this sense, Kamala, Kamaswami and the river, all are in the active role of a teacher who teaches different things to Siddhartha.

Siddhartha's acquisitions of two skills for his previous teachers are a must to engrave his path for self- enlightenment. Here, his mastering "to speak Om silently" while inhaling and while exhaling from his father and art of thinking, waiting and fasting and thinking from Samanas are important (03/42). For example, he won the heart of Kamala and Kamaswami by enchanting them with skills that only a samana possessed. Though he was on his way of education through sense, he unhesitatingly confirmed his spiritual quality that he can think, he can wait and he can fast. Siddhartha proved that he is unique and he is confident because he earned qualities which are unique and rare. More than that, in the climax of his journey of enlightenment was when he tried to kill himself regretting his past sensual life with Kamala, the word Om resounded the way it was resounded to him when he was practicing it with his father long ago. Siddhartha himself described how the resounding OM saved his life and opened his way for enlightenment as "out of remote areas of his soul, out of past times of his now weary life, a sound stirred up. It was a word, a syllable ...the holy "Om" (65). This realization of Om was a turning point in his success over getting self- enlightenment. It is the very Om that his gurus and father had taught him at his home.

Siddhartha's passion for self- enlightenment got its roots in Gotama's sermons. Before meeting Gotama, he was in search of teachers that could lead him to the path of 
salvation. However, the very first sermon of Gotama enlightened him, and he got a supreme understanding that salvation cannot be touched. This is why he left Gotama and went in search of self-salvation. Though the idea of self-salvation is very questionable here, it was supported by different critics. In his article "Education is Self-Education," Gadamer (2001) defends the ideas of self-education and writes "Education is to educate oneself" (p. 529). Similarly, in his study of Siddhartha, Malthaner (1952) supported Siddhartha's attempt for self- salvation and said that it is the only way for his attainment of salvation. Justifying his ideas Malthaner said that "it becomes clear to him that the way salvation cannot be taught...so he also leaves Gotama and all the teachers and teaching" (p. 106).

The idea of self- education of Gadamer and Malthaner ideas of salvation (which is only possible through enlightenment) is countered by the story of Ekalavya, who tried to achieve the highest state in archery, in Mahabahrat (Saurya Veer Ekalavya Ki Gatha, episode 49). In the epic, Ekalavya though not directly participated in the teaching of Dronacharya, the royal guru, offered the thumb of his right hand to him as a gurudaxina, fee for the knowledge that he gained under his motivation. Here, the sacrifice of Ekalavya proves that our motivation, which we call internal/ personal, may have its source outside. Whether the source may be with direct participation or just a motivation, we must acknowledge it.

Unlike Ekalavya, Siddahrtha also acknowledges the role of teachers in his education- but in the latent level. Though he denies linking his source of knowledge to his gurus, we find a lot of contradiction in his in his beliefs. Analyzing what he learned from Gotama Siddhartha accepted that though he had not learned anything from him "but he has given me Siddhartha, myself" (28). This acceptance of Siddhartha hints for the fact that the presence of Gotama, as a teacher, is at the central of his ideas of self-enlightenment.

However, Siddhartha has chosen his own way for the path- that is enlightenment through the use of senses. His time with Kamala was full of sensual and physical love, which he called living in samsara. He learned "joy of love" from Kamala and art of doing business from Kamalaswami (41). Nevertheless, he soon realized that unconditional use of senses too do not open his way for salvation. He realized the foolishness of his action and decided "starting again at the beginning and as a child" (70). 
Siddhartha's new life, which continues the knowledge that he took from his previous teacher, is the life in which he gets the enlightenment that he wanted. However, the enlightenment is not a result of his self- knowledge. Rather it is the result of his revision of knowledge from past teachers and guardianship of present teachers: Vasudeva and the river. Though not professional, still Vasudeva and the river play the role of the teacher as a guide (Shim, 2008, p. 515). Siddhartha spent his last phase of his journey of enlightenment with Vasudeva who guided him and imparted his different knowledge regarding the mystery of life. More than Vasudeva, the role of nature as a teacher is important here. Nature is such a great teacher which remains silent but teaches better than human enlightened figures. However, anyone may not take any education from nature. Only a person who is passionate about learning and high level of concentration can do that. Emphasizing the power of nature on increasing the level of understanding by avoiding stress, Berto (2014) writes "Exposure to nature is a coping strategy, which has positive effects both on arousal level and cognitive overload" (p. 395).

Here, the way Bruto says the river works as a healing power to Siddhartha. The ideas that he understands by studying the message forwarded by the river arouses that level of understanding that leads him to understand those things that he could not understand up to this time. There may be a surface doubt that it is possible to learn from a source which does not communicate at all. Such a doubt is clear as we analyze it with the perspective of non-verbal communication- that we do by using sound, manner, physical get up and physical proximity (Bovee and Thill, 2018, p. 58- 60). In the story, the more Siddhartha goes near the river, the more he spends time with the river, and the more he goes closer to enlightenment. As non- verbal signals can communicate stronger than verbal ones, "Siddhartha understands many other things, many secrets, all secrets" from the river that is unrevealed to him up to this time (75).

Still, there is another question to answer to prove that his enlightenment was nothing but a shadow of his previous teachers. Siddhartha denied the presence of the teacher because he believes that he gets self- enlightenment by exploring his own self. However, exploring the inner self is like searching for a new teacher for further knowledge 
in life. Our mortal self and the inner soul are not the same- they are different. Therefore, learning from it is not an independent activity because "even while a person is reading a book or talking to himself, he or she interacts with a second self- the book of the writer or his own self" (Shim, 2008, p. 516). Thus, getting knowledge understanding the self is not getting knowledge without a teacher. Siddhartha's inner soul was unfamiliar to him up to this time; he was just able to know it after getting knowledge from different sources. Soul cannot give knowledge on its own. This is why, in Shreemad Bhagwat Geeta, Lord Krishan says that soul does not have its own knowledge; it needs a teacher to guide it; then only it can reflect the knowledge in which a person can see the whole world and understand every mystery within his own self (Annie and Das, 1905, Chapter 4, Verse 35). Here, Siddhartha's learning from own soul too deconstructs his ideas of self-salvation. That is, his learning from self- conversation is not self- enlightenment; rather it is only a reflection of a shadow under the guidance of his teachers.

\section{Conclusion}

After studying Siddhartha's characters, the nature of his journey for salvation and his interaction with the people whom he encounters during the journey show his selfsalvation has its seeds from outside. During the journey he met and left different teachers to understand the mystery of life but only understood the thing at the end when he was alonethough not without teachers. This entire incident in his life proves teaching and learning activities go together and it is impossible to receive teaching activities without any involvement of teachers (Shim, 2008, p. 515). In other words, his journey of self- salvation seems to be the journey of understanding the mystery of Om, which was started from beginning- when he started his education at home and ended when got succeeded only with the companionship with Vasudeva and the river. Siddhartha's journey of so-called enlightenment started with the practice of realizing Om and ended with the realization of Om. When he was a child he practiced the same Om with his father and other gurus, (he practiced it with Gotama and samana) and how he realized the same word with the help of Vasudeva and the river. 


\section{References}

Berto, Rita. (2014). The role of nature in coping with psycho- physiological stress: A literature review on restorativeness. Behavioural Science, 4, 394- 409. Retrieved from https://www.mdpi.com/2076-328X/4/4/394.pdf.

Besant, Annie and Das,Vagavan (1905). The vagavad- gita. TheosoPhical Publishing Society. London and Benares. Retrieved fromhttps://www.sturuguay.org/ libros/Revistas/ THE\% 20INDIAN \% 20THEOSOPHIST.pdf.

Big Magic. (April 18, 2018). Sourya veer eklavya ki gatha (video). Retrieved form https://www.youtube.com/watch? $v=2-Z N s Z P W-v g \& t=841 \mathrm{~s}$

Bovee, L. Cortland and Thill, V. John. (2010) Business communication today. Pearson India Education Services Pvt.Ltd.

Bristow, William. (2017). Enlightenment. The Stanford Encyclopedia of Philosophy. Edward N. Zalta (ed.). Retrieve from <https://plato.stanford.edu/archives/ fall2017/entries/enlightenment/> Colebrook, Claire. (2004). Irony. Routledge. Retrieved from https://books. google.com.np/booksh.pdf.

Gadamer, H. Geroge. (2001) Education is self- education. Journal of Philosophy of Education, Vol., 35, No. 4. Retrieved from http://mural.maynoothuniversity. ie/8592/1/Gadamer-2001-Journal_of_Philosophy_of_Education.pdf.

Grenz, J. Stanley. (1996). A primer on postmodernism. Wiiliam B. Eerdmans Comapany. Cambridge, UK. Retrieved from. https://books.google.com.np /books? hl=en\&lr= $\& \mathrm{id}=\mathrm{gBTTKIqz} 5 \mathrm{mEC} \& \mathrm{oi}=$ fnd $\& \mathrm{pg}=\mathrm{PP} 11 \& \mathrm{dq}=\mathrm{a}+$ primer + on + postmodernism.

Hart. S., Dixon. A., Drummond. M.J., \& Mclntyre. D. (2004). Learning without limits. Open University Press. Retrieved from https://books.google.com.np/books? $\mathrm{hl}=$ en\&lr=\&id=t5ZexwkBLioC\&oi=fnd\&pg=PP1\&dq=susan+hart+learning + witho ut + limits.

Hesse, Herman. (2010). Siddhartha. Icon Classics. 
Lesikar V. Raymond and etit D. John. (1996.). Business communication: Theory and application. All India Traveller Bookseller, India. 6xth Ed. ISBN $8185386056 .$.

Malthaner, Johanness. (1952, March). Hermann Hesse. Siddhartha. Published by Willey. Source the German Quarterly, Vol, 25, No. 2, 103- 109.

Shim, Seung Hwang. (2008). A philosophical investigation on the role of the teachers: A synthesis of Plato, Confucious, Buber, Freire. Teaching and Teacher's Education, 24, 515- 535.

Utram, Dorinda (2019). The Enlightenment. Cambridge University press. Goole Scholar. https://books.google.com.np/books?hl=en\&lr=\&id=yjCdDwAAQBAJ\&oi=fnd\&pg $=$ PR8\&dq=related:8cWU-XGHe5MJ:

Yan, Sanghais. (2012). Teachers role in autonomous learning. Lanzhou University of Technology. Lanzhou, China. doi:10.5296/jsr.v3i2.2860 